\title{
Introduction of medical abortion in Ghana
}

\author{
Emmanuel Kuffour \\ Population Council \\ Selina F. Esantsi \\ Population Council \\ Placide Tapsoba \\ Population Council \\ Gloria Quansah Asare \\ Ian Askew \\ Population Council
}

Follow this and additional works at: https://knowledgecommons.popcouncil.org/departments_sbsr-rh

Part of the Demography, Population, and Ecology Commons, Family, Life Course, and Society Commons, Health Policy Commons, International Public Health Commons, Obstetrics and Gynecology Commons, Public Health Education and Promotion Commons, and the Women's Health Commons How does access to this work benefit you? Let us know!

\section{Recommended Citation}

Kuffour, Emmanuel, Selina F. Esantsi, Placide Tapsoba, Gloria Quansah Asare, and lan Askew. 2011. "Introduction of medical abortion in Ghana." Accra: Population Council. 


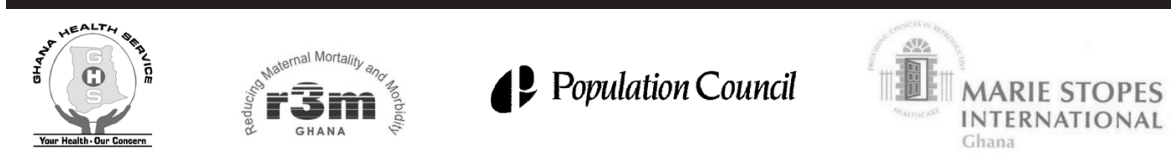

\section{INTRODUCTION OF MEDICAL ABORTION IN GHANA}

Emmanuel Osei Kuffour ${ }^{1}$, Selina F. Esantsi ${ }^{1}$, Placide Tapsoba ${ }^{1}$, Gloria QuansahAsare $^{2}$, Ian Askew ${ }^{3}$

Emmanuel Osei Kuffour PhD (abd); M\&E Advisor, Population Council, Ghana,

Selina F. Esantsi, MA; Program Officer, Population Council, Ghana

Placide Tapsoba, MD, MPH; Director, Population Council, Ghana

Gloria Quansah-Asare, MD, PhD; Director of Family Health Division,

Ghana Health Service

Ian Askew Ph.D; Director, Reproductive Health Services and Research, Population Council 


\section{(2) Population Council}

The Population Council is an international, nonprofit, nongovernmental organization that seeks to improve the well-being and reproductive health of current and future generations around the world and to help achieve a humane, equitable, and sustainable balance between people and resources. The Council conducts biomedical, social science, and public health research ad helps build research capacities in developing countries. Established in 1952, the Council is governed by an international board of trustees. Its New York headquarters supports a global network of regional and country offices.

(C) 2011 The Population Council, Inc.

Population Council

14B Ridge Road, Roman Ridge Accra, Ghana

Tel: +233-30 2780711/2

Fax: +233-30 2780713

E-mail: pcaccra@popcouncil.org
Population Council

One Dag Hammarskjold Plaza

New York, NY 10017 USA

Tel: (1) 212-339 0500

Fax: (1) 212-755 6052

www.popcouncil.org 


\section{Table of Contents}

List of Tables.......................................................... iv

Acknowledgement .................................................. 1

Executive Summary................................................. 4

Background ........................................................ 7

Research Methodology................................................ 11

Study Population .................................................... 11

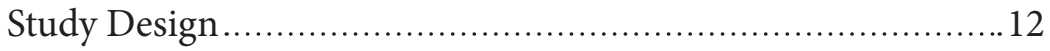

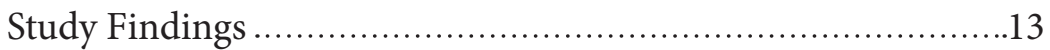

Socio-Demographic and Economic Characteristics

of Clients ........................................................... 13

Fertility Experience of Clients Interviewed ...................14

Assessment of Medical Abortion Service Provision........15

Experience with the Medical Abortion Procedu.............16

Known Side Effects of Medical Abortion ....................... 19

Service Providers' Training and Knowledge about

Medical Abortion................................................... 20

Satisfaction and Acceptance of Medical Abortion ..........22

Difficulties and Challenges of Medical Abortion in Ghana .............................................................. 23

Scaling up and Sustainability of Program and Product

Services ....................................................... 25

Conclusion ............................................................ 26

Reference ......................................................... 29 


\section{List of Tables}

Table 1: Pregnancies and Children Ever Born ...........................15

Table 2: Reasons for Selection of Medical Abortion....................16

Table 3: Location Preference for Mediprist Administration ..... 17

Table 4: Location for Misoprostol Administration.....................17

Table 5: Person Present during Administration of

Medical Abortion ............................................ 18

Table 6: Time Taken for Complete Expulsion after Misoprostol.... 18

Table 7: Known Side Effects of Mediprist.............................. 19

Table 8: Known Side Effects of Misoprostol ..............................19

Table 9: Ranked Provider Knowledge on Medical Abortion

Drug Administration

Table 10: Service Provider Knowledge of Ineligibility

Criteria for Mediprist.

Table 11: Percent Distribution of Clients by Level of

Satisfaction

Table 12: Provider Challenges Associated with Medical Abortion..23

Table 13: Distribution of Worst Experience by Clients 24

Table 14: Percent Distribution of best Experience of Procedure

by Clients 25

Table 15: Study Sample by Socio-Demographic Characteristics..... 31 


\section{Acknowledgement}

This documentation process was jointly undertaken by the Ghana Health Service, the Population Council and Marie Stopes International Ghana (MSIG). The study team acknowledges with gratitude the support from staff of Marie Stopes International especially, Mrs. Faustina FynnNyame, Mr. Frank Otchere, Mr. Fred Gbagbo, Mr. Selase Adjei and Mr. Wise Agbetsiafa. We would also like to appreciate the substantial contribution of Mr. Nathaniel Yellu (Ghana Health Service/Research Development Division) and Mr. Abu Mumuni (Regional Institute of Population Studies) who assisted with interviewer training, fieldwork and initial report preparation.

We acknowledge theimmense assistance received from the management and staff of the documentation sites: Marie Stopes International - Ghana centers of excellence at Kokomlemle, Ashiaman, Tema Manhean and Kumasi; Ridge Hospital; La General Hospital; Korle Bu Teaching Hospital; Koforidua Regional Hospital; Manhyia Government Hospital and Oda Government Hospital for the significant role they played in the implementation of the study. We especially thank the providers for their assistance in coordinating interview appointments with clients. Without their patience in these coordination efforts and continuous reminders to clients, the data gathering process would not have been smooth. We are also very grateful to Dr. Gloria Quansah-Asare, FHD/ GHS for her thorough review of the research protocol and instruments and also for her very useful comments

Our sincere gratitude goes to the data collection team and the data entry staff who worked tirelessly to collect and enter the data used in the preparation of this report. This study would not have been possible without the clients who were kind and patient enough to respond to questions from the interviewers. 
Finally, we wish to acknowledge the support of both technical and administrative staff of the three collaborating organizations (Population Council, Marie Stopes International and the Ghana Health Service) for working diligently towards the successful planning and implementation of the intervention and data collection activities. 


\section{List of Acronyms}

CAC

COMPREHENSIVE ABORTION CARE

DHS

DEMOGRAPHIC AND HEALTH SURVEYS

$\mathrm{D} \& \mathrm{C}$

DILATION AND CURETTAGE

$\mathrm{D} \& \mathrm{E}$

DILATION AND EVACUATION

EVA

ELECTRIC VACUUM ASPIRATION

FDB

FOOD AND DRUGS BOARD

FP

FAMILY PLANNING

GHS

GHANA HEALTH SERVICE

MA

MEDICAL ABORTION

$\mathrm{MOH}$

MINISTRY OF HEALTH

MSIG

MARIE STOPES INTERNATIONAL GHANA

MVA

MANUAL VACUUM ASPIRATION

$\mathrm{R} 3 \mathrm{M}$

REDUCING MATERNAL MORBIDITY AND

MORTALITY

SRH

SEXUAL AND REPRODUCTIVE HEALTH

WHO

WORLD HEALTH ORGANIZATION 


\section{Executive Summary}

Unsafe abortion has been acknowledged as one of the major causes of maternal mortality and morbidity in Ghana. According to the 2007 Ghana Maternal Health Survey report, 11\% of the reported 451 maternal deaths were abortion related (Macro International, 2009). With limited numbers of trained service providers and well equipped facilities to provide surgical abortions, medical non-surgical methods of terminating pregnancies promises an additional way of increasing access to safe abortion services as permitted by law and contributing to reducing maternal mortality and morbidity (Medical Abortion, 2009).

To support the government's effort in achieving MDG 5, in September 2006, a consortium of five (5) agencies consisting of EngenderHealth, Ipas, Marie Stopes International - Ghana (MSIG), Population Council and Willows Foundation, in collaboration with the MOH/GHS and with funding from an anonymous donor, initiated a program named Reducing Maternal Mortality and Morbidity (R3M). The program provides the commitment, financial and technical resources that enable the government to expand significantly women's access to modern family planning and comprehensive abortion care (CAC) services. MSIG's focus is in the provision of family planning and comprehensive abortion care services in the private sector. MSIG's mandate also includes the piloting and registration of new technologies and procedures for abortion care management; a provisional license was awarded to MSIG by the Ghana Food and Drugs Board (FDB) for the introduction and provision of the first medical abortion regimen (Mifepristone and Misoprostol) in Ghana. Population Council conducted this study to document this introduction process, findings from the study will provide the much needed evidence based report to inform policy decision making and the scale-up phase.

The study involved a total of ten health facilities: (4) MSIG centers: Ashiaman and U-Compound in Tema, Kokomlemle in Accra and Kumasi and (6) public health facilities: Korle Bu Teaching Hospital, 
Ridge and La General Hospitals in Greater Accra Region, Koforidua Regional and Oda Government Hospitals in Eastern Region and Manhyia Hospital in Ashanti Region. The research team interviewed a total of 477 clients and 13 health providers. However, due to missing/ incomplete data 461 client and all 13 provider interview data was used for the preparation of this report.

The study aimed at documenting the introduction of the dual regimen; Mifepristone and Misoprostol for early pregnancy termination. The study also examined health providers' skills, quality of services delivered, and clients' satisfaction with the method and provider-patient interpersonal rapport among others. The results show that the mean age of clients who sought medical abortion services was about 26 years. Thirteen (13) percent of all interviewed clients were teenagers between the ages of 15 and 19 years. The majority of clients (55\%) had never been married while the average number of pregnancy experienced was about three (3). Eighty three (83) percent of the interviewed clients had at least completed primary education with about $24 \%$ still being students. Out of the providers interviewed, 10 were midwives, two (2) were general nurses and one was a medical assistant. Ninety two percent of all interviewed providers showed good and adequate knowledge in medical abortion service provision procedures, almost all, 12 out of 13 service providers knew the accurate and recommended dosage of Mediprist.

Results also revealed that about $50 \%$ of the clients who visited the facilities had medical abortion in mind whiles the rest had MVA/EVA in mind. Approximately $93 \%$ of all the clients reported that in making a choice, they were provided with sufficient information on the two methods available. A total of $73 \%$ of all clients' reasons for choosing medical abortion over surgical abortion was to avoid anesthesia, surgery, risk of complications and pain.

After an initial dose of Mediprist, the reported expulsion time of the product of conception for over $80 \%$ of clients was within 24 hours 
after administration of Misoprostol. For 16\% of interviewed clients, complete expulsion occurred after 24 hours, to complete the expulsion process for the remaining four (4) percent of clients who had reported that the product of conception was not expelled, an additional dose of Misoprostol was given/surgical completion was done at no cost to them.

The most common side effects mentioned were cramps and bleeding after the Mediprist and Misoprostol respectively, three in five clients used a pain medication during the process.

Acceptability of medical abortion procedure was very high; about $81 \%$ of the clients indicated that they will use the method again if they had to, while about $90 \%$ indicated that they will recommend the method to their family and friends; approximately $85 \%$ of the providers were satisfied with the procedure.

\section{RECOMMENDATIONS}

- Scale-up is encouraged given the high success rate with the medical abortion combined regimen at the study sites.

- Service providers need to be given a thorough orientation on medical abortion counseling and service provision.

- Family planning counseling should be a major part of the follow up visit.

- Use of effective contraceptive method should be strongly encouraged to all clients.

- Clients need to be given adequate information about the processes/stages, highly encouraged to return for the followup visits. 


\section{Background}

The term medical abortion refers to pregnancy termination with abortion-inducing medications in lieu of primary surgical intervention (Creinin, 2000). Although the idea of using medications to induce abortion has been around for centuries, evidence-based regimens for use in the first trimester of pregnancy only became a reality in the last 25 years. An estimated 22 unsafe abortions occur for every 1000 women globally. An alarming fifth of all maternal deaths in Africa are due to complications arising from unsafe abortions. With limited numbers of trained service providers and fully equipped facilities to provide surgical abortions, medical non-surgical methods of terminating pregnancies promises an additional way of increasing access to safe abortion services and contributing to reducing maternal mortality and morbidity.

Like most countries in sub-Saharan Africa, Ghana suffers from high maternal mortality and morbidity due partly to high rates of unwanted fertility and unsafe abortion and relatively low use of modern contraception. Although the Government of Ghana has made impressive gains in recent years, access to reproductive health services remains poor, particularly so for the majority of the population who live in rural, impoverished, and isolated communities. Only 17 percent of married women of reproductive age use modern contraceptive methods (Macro International 2009), and data from the 2008 Ghana Demographic and Health Survey indicates that 14 percent of all births in Ghana are unwanted, 37 percent are unplanned, and 23 percent are mistimed (Macro International 2009). Mistimed, unplanned, and unwanted fertility arise from limited access to and use of family planning services.

In Ghana abortion is a criminal offence regulated by Act 29, section 58 of the Criminal code of 1960, amended by PNDCL 102 of 1985 (Criminal Code of Ghana, 1960). It states that: 
1. Subject to the provisions of subsection (2) of this section

a. Any woman who with intent to cause abortion or miscarriage administers to herself or consent to be administered to her any poison, drug or other noxious thing or uses any instrument or other means whatsoever; or

b. Any person who

i. Administers to a woman any poison, drug or other noxious thing or uses any instrument or other means whatsoever with intent to cause abortion or miscarriage, whether or not the woman is pregnant or has given her consent;

ii. Induces a woman to cause or consent to causing abortion or miscarriage;

iii. Aids and abets a woman to cause abortion or miscarriage;

iv. Attempts to cause abortion or miscarriage; or

v. Supplies or procures any poison, drug, instrument or other thing knowing that it is intended to be used or employed to cause abortion or miscarriage; shall be guilty of an offence and liable on conviction to imprisonment for a term not exceeding five years.

2. It is not an offence under section (1) if an abortion or miscarriage is caused in any of the following circumstances by a registered medical practitioner specializing in gynecology or any other registered medical practitioner in a government hospital or a private hospital or clinic registered under the Private Hospital and Maternity Home Act, 1958 (No. 9) or in a place approved for the purpose by legislative instrument made by the Secretary:

a. Where pregnancy is the result of rape or defilement of a female idiot or incest and the abortion or miscarriage is requested by the victim or her next of kin or the person in loco parentis, if she lacks the capacity to make such request;

b. Where the continuance of the pregnancy would involve risk to the life of the pregnant woman or injury to her physical or mental health and such a woman consents to it or if she lacks the capacity to give such consent it is given on her behalf by her next of kin or the person in loco parentis; 
c. Where there is substantial risk that if the child were born it may suffer from or later develop a serious physical abnormality or disease.

3. For the purposes of this section Abortion or miscarriage means premature expulsion or removal of conception from the uterus or womb before the period of gestation is completed.

The above thus allow Ghanaian women the legal option to terminate an unwanted pregnancy. Despite this "liberal" law, implementation of programs to match the policy intentions has been slow; moreover, knowledge of safe abortion services is also not widespread among communities. Information gaps remain in key areas such as systematic documentation of the implementation of the law; the various service models for safe abortion services; methods for monitoring quality of care of services; technical resources and updated information of technologies and procedures.

In 2006, a consortium of five agencies; EngenderHealth, Ipas, Marie Stopes International, Population Council, and the Willows Foundation came together to provide technical and financial support to the Government of Ghana in the provision of family planning and CAC services. The consortium collaborates with the Government of Ghana in expanding women's access to modern family planning and comprehensive abortion care. The consortium's program titled "Reducing Maternal Morbidity and Mortality" (R3M) program, aims to increase access to FP services and reduce unwanted pregnancy and severe complications and deaths caused by unsafe abortions.

As part of the R3M program, Marie Stopes International Ghana (MSIG) is providing family planning and comprehensive abortion care services in the private sector. MSIG has established four static "centers of excellence" clinics, three in Accra and one in Kumasi. These centers provide a range of sexual and reproductive health services (SRH) at affordable prices. Part of MSIG's mandate is to increase access to and 
utilization of quality, sustainable CAC and FP services through the establishment of a network of franchised service delivery centers. A total of 100 franchisees comprising 42 Clinics, 25 Pharmacy shops and 33 Chemical sellers have been recruited and receive technical support and SRH commodities from MSIG. These franchisees also serve as referral points for the MSIG Centers. MSIG's mandate also includes the introduction of new technologies and procedures for abortion care and management.

Mifepristone, branded by MSIG as MEDIPRIST, has been granted temporary approval and permission by the Ghana Food and Drugs Board (FDB) to be used as a medical abortifacient. Together with Misoprostol which has already been approved for use in Ghana by FDB, the two regimen combination will be used for the medical abortion procedure; an oral administration of $200 \mathrm{mg}$ Mifepristone (MEDIPRIST) ideally in the health facility followed by an oral administration of $800 \mathrm{mg}$ misoprostol 24-48 hours later either in the facility or any other place of choice for the woman. Complete approval will be granted primarily based on the outcome of this documentation process. The FDB registration process includes stringent measures for documenting usage; one registration condition was for the introduction to be channeled only through MSIG centers, franchisee clinics and selected GHS service delivery sites for an initial introductory period during which time the process will be documented. All providers in the implementation sites received training from MSIG, the training included an overview of the product information, including dose regimen, efficacy, side effects, contra-indications, counseling, and general norms and procedures for provision of medical abortion.

This study was undertaken by the Population Council as an unbiased evaluator, taking the lead role in the documentation process to objectively report on the introduction of the combination regimen Mediprist and Misoprostol as a Medical Abortifacient. The findings from this study will inform all stakeholders and lessons learnt will serve as a guide to MSIG and Ghana Health Service as a whole during the scale-up stage. 


\section{Study Objectives}

The primary objective of this study was to document the introduction of Mifepristone and Misoprostol for early medical abortion in Ghana.

The specific objectives were to:

1. Assess the ability of providers and early experience of providers in the provision of the new regimen;

2. Document the quality of care of abortion services offered at both private and public health facilities;

3. Document client satisfaction with the medical abortion procedure;

4. Document all client side/adverse effects experienced;

5. Discuss lessons learnt for further refinement and modification before scaling up.

\section{Research Methodology}

\section{Study Population}

The study population was women in their reproductive age (15 - 49 years old) who sought abortion services from designated facilities in Accra, Ashanti and Eastern regions. For a woman to be eligible for the study, she was expected to be in general good health and must have been assessed by a clinician to have an intrauterine pregnancy that was less than 49 days on the first day of contact with the study team. Only the clients who after counseling on the two available methods chose medical abortion were included in the study. The study used the following as criteria for selecting eligible women for the study. The woman must:

- Be willing to participate, consent and be able to endorse an informed consent form by signature or thumbprint

- Client's desire to terminate pregnancy

- Be eligible for medical abortion according to the clinician's 
assessment

- Be willing to undergo a surgical completion of the abortion if necessary

- Have ready and easy access to a telephone or mobile phone

- Agree to comply with the study procedures and visit schedule

The study considered women with any of the following conditions as ineligible for the study:

- Confirmed or suspected ectopic pregnancy or undiagnosed adnexal mass

- Chronic renal failure

- Concurrent long-term corticosteroid therapy

- History of allergy to mifepristone, misoprostol or other

- Prostaglandin

- Hemorrhagic disorders or concurrent anticoagulant therapy

- inherited porphyria

- Possible ectopic pregnancy

- IUD/IUS in place

- other serious physical or mental health conditions

\section{Study Design}

The study was facility-based: four MSIG static centers in Kumasi and Accra; and six public health facilities, KBTH, Ridge and La General Hospitals in Greater Accra Region, Koforidua Regional Hospital and Oda Government Hospital in Eastern Region and Manhyia Hospital in Ashanti Region were the study sites. Inclusion of both public and private health facilities allowed for documentation of the process in the two settings where services will normally be provided and also provided a wide range of clients with different backgrounds and experiences.

As stated above, all women in the study received $200 \mathrm{mg}$ Mediprist orally at the facilities during the initial visit followed by an oral administration of $800 \mathrm{mg}$ misoprostol $24-48$ hours later either in the facility or any 
other place of choice for the client. All clients were required to return to the facilities in 10-14 days for a follow up examination to ensure complete expulsion, during this visit, clients will be counseled and provided with their choice of a family planning method to prevent future unintended pregnancies. As part of the initial counseling, the importance of the follow-up examination visit is stressed to clients and they are also provided with token funds to assist with their transportation expenses for the follow-up visit, a combination which allowed a high client return rate. Client exit interviews were conducted immediately after the completion of the examination during follow up visit. Service providers who offered medical abortion services were also interviewed. The study team included interviewers who were each assigned to each of the study sites for the duration of the study. The women were identified at first visit and then interviewed after they completed the review visit. Data collection was conducted over a period of 5 months.

\section{Study Findings}

\section{Socio-Demographic and Economic Characteristics of Clients}

The study interviewed 477 women in their reproductive age (15 - 49 years old) across ten health care service delivery facilities in three administrative regions of Ghana namely Greater Accra, Ashanti and Eastern Regions. These ten health facilities comprise six tertiary care public health institutions; Koforidua Regional Hospital, KBTH, La General Hospital, Manhyia Government Hospital, Oda Government Hospital and Ridge Hospital; and 4 Marie Stopes International centers of excellence in Ashiaman, Kokomlemle, Manhean and Kumasi. The socio-demographic and economic characteristics of clients are shown in Appendix. About three out of five (58.9 percent) clients were residents of Accra, 11.7 percent resided in Kumasi and approximately 4.5 percent were residents of Koforidua. The remaining 24.9 percent were residents of nearby communities around Accra, Tema, Kumasi 
and Koforidua and others coming from Nsawam and Ofoase in the Eastern Region and as far as Bolgatanga in the Upper East.

A mean age of 25.8 years was reported among clients interviewed with 13.2 percent in their teen years and the rest distributed across the other age groups (Table 1). More than half (55.0 percent) had never been married, 26.3 percent were married, 15.8 percent were in consensual unions (cohabiting) and the remaining three percent were widowed, divorced or separated.

About six percent (6.3 percent) of the clients had no formal education, more than half (55.6 percent) had secondary or higher education and the rest had primary or basic education. The majority of clients interviewed, 89.5 percent were Christians and 8.6 percent were of the Islamic faith, the others belonged to a traditional religion or had no religion. About 49.2 percent of clients interviewed belonged to the Akan ethnic group while the rest were distributed among Ewe, GaDangme, Mole Dagbani, Guan, and other ethnic groups. About one in ten clients were unemployed with a little over a quarter (26.5 percent) employed in the professional/clerical/technical field, 23.6 percent were students and about twenty two percent were traders (22.3 percent).

\section{Fertility Experience of Clients Interviewed}

The mean children ever born among the study sample is relatively lower than the mean number of pregnancies experienced. While the average number of children born (live birth) is approximately one child, the average number of pregnancies experienced is about three as seen in Table 1. The maximum number of pregnancies experienced by any client in our sample is 16 while the highest number of live births is 11 children. The average preferred number of children for our client sample is about three children. The table does highlight an interesting fertility behavior pattern worth noting, it shows that on average the clients have had 1.5 more pregnancies than live births, i.e. most women interviewed have had 1-2 abortions (or miscarriages) before this visit. 
Yet, although on average they currently have 1 child, they would prefer to have at least 3 children. A question which we do not address in this paper is why are these women having repeated abortions when the average preferred number of children and live births is three and one respectively?

Table 1: Pregnancies and Children Ever Born

\begin{tabular}{lccccc}
\hline \hline Variable & Mean & Min & Max & $\begin{array}{c}\text { Std. } \\
\text { Deviation }\end{array}$ & Number \\
\hline Preferred \# of children & 3.1 & 0 & 10 & 1.2 & 461 \\
Pregnancies & 2.5 & 0 & 16 & 1.9 & 461 \\
Live birth & 1.0 & 0 & 11 & 1.4 & 461 \\
Living children & 0.9 & 0 & 8 & 1.3 & 461 \\
& & & & & \\
\hline \hline
\end{tabular}

\section{Assessment of Medical Abortion Service Provision: Client Perspective}

During the initial consultation with service providers on the various methods of pregnancy termination, almost nine in ten (88.7 percent) clients indicated that MVA/EVA was mentioned and discussed with them. Almost all (99.4 percent) indicated that the medical abortion process and eligibility requirements were discussed with them. About 46 percent (212) of clients who came to the health facility had some particular pregnancy termination method in mind. Among these clients, about half (50.9 percent) had medical abortion in mind, about 48.1 percent had termination by MVA/EVA in mind and the rest mentioned Cipro, D\&C.

About 93.1 percent of the clients reported that they felt that the service providers gave sufficient information on available options for pregnancy termination during their first counseling consultation. The majority, 90.2 percent and 92.0 percent respectively indicated they had the opportunity to ask questions and chose a preferred method for their pregnancy termination. The distribution of the most important reasons for deciding to use medical abortion is shown in Table 2. The 
most mentioned reason for deciding to use medical abortion was to avoid surgery (31.2 percent), and to avoid physical trauma or pain (25.4 percent). About one percent of the clients mentioned more than one reason for deciding to use medical abortion instead of surgical abortion.

Table 2: Reasons for Selection of Medical Abortion

\begin{tabular}{lcc}
\hline & \multicolumn{2}{c}{ Responses } \\
\cline { 2 - 3 } \multicolumn{1}{c}{ Reasons } & Number & Percent \\
\hline To avoid surgery & 144 & 31.2 \\
To avoid physical trauma/pain & 117 & 25.4 \\
It is less risky/no complications & 47 & 10.2 \\
It was recommended by a friend & 41 & 8.9 \\
Was offered no other option & 25 & 5.4 \\
It is less expensive & 23 & 5.0 \\
To avoid anesthesia & 16 & 3.5 \\
It is less invasive & 10 & 2.2 \\
It is more effective & 7 & 1.5 \\
Other reasons & 14 & 3.0
\end{tabular}

\section{Experience with the Medical Abortion Procedure}

Clients visit the health facilities, they are first counseled on the available options and eligibility criteria. As part of the counseling for the medical abortion procedure, the clients are informed of the regimen, the mode(s) of administration of the medication(s) and are also told about the option to take the second medication, either at the facility or at home. All clients had the first drug, Mediprist administered at the clinic. As shown in Table 3, approximately 68 percent of the clients indicated that they would have preferred to take the Mediprist at the 
clinic, with about 28 percent preferring to take it at home.

\begin{tabular}{lcc} 
Table 3: Location Preference for Mediprist Administration \\
\hline \hline & \multicolumn{2}{c}{ Responses } \\
\cline { 2 - 3 } Preference & Number & Percent \\
\hline Clinic & 313 & 67.9 \\
Home & 129 & 28.0 \\
Not Terminate Again & 11 & 2.4 \\
Indifferent & 8 & 1.7 \\
Total & 461 & 100 \\
\hline \hline
\end{tabular}

\begin{tabular}{lcc}
\multicolumn{2}{c}{ Table 4: Location for Misoprostol Administration } \\
\cline { 2 - 3 } Preference & \multicolumn{2}{c}{ Responses } \\
\hline Clinic & Number & Percent \\
Home & 180 & 60.7 \\
Total & 461 & 39.3 \\
\hline \hline
\end{tabular}

More than half (60.7 percent) of clients interviewed had the second drug, Misoprostol also administered at the clinic, with 39.3 percent taking the Misoprostol outside the clinic, three clients did not take the Misoprostol. Table 4 shows the total number of clients who took Misoprostol outside the health facility. Out of this number, 72 of them reported having someone with them when they took the medicine; Table 5 shows the distribution of the people who were present with the client. About 61 percent of the clients indicated having their partner present, 21 percent had their friends present when the drug was taken and only three percent of clients who took the Misoprostol outside the health facility had their mother present when they took the medication. 
Table 5: Person Present during Administration of Misoprostol

\begin{tabular}{lcc}
\hline & \multicolumn{2}{c}{ Responses } \\
\cline { 2 - 3 } Person Present & Number & Percent \\
\hline A husband/boyfriend & 43 & 60.6 \\
A friend & 15 & 21.1 \\
Mother & 2 & 2.8 \\
Other relatives & 6 & 8.5 \\
Others & 6 & 7.0 \\
Total & 72 & 100.0 \\
\hline \hline
\end{tabular}

About three in ten (28.7 percent) clients indicated they experienced the onset of expulsion after taking Mediprist. Complete expulsion usually happened within the first 6 hours after taking the second medication, Misoprostol. About 80 percent experienced complete expulsion within the first 24 hours after administering Misoprostol as shown in Table 6. Approximately two percent needed an additional dose of Misoprostol for complete expulsion. About 9 clients did not experience any expulsion after taking the medication and had surgical completion at no cost to them. This conforms with other studies that have shown that generally under $5 \%$ of women who go in for medical abortion do not experience any expulsion and would need a suction procedure to complete it (Spitz et. al, 1998). The success rate in this study is quite high and could be explained by the relatively low gestational age cap. hours of vaginal dose (WHO 2003)

Table 6: Time Taken for Complete Expulsion after Misoprostol

\begin{tabular}{lcc}
\hline \hline Length of Time & Number & Percent \\
\hline Less than 6 hours & 186 & 40.3 \\
Between 6-12 hours & 100 & 21.7 \\
Between 12-24 hours & 84 & 18.2 \\
More than 24 hours & 75 & 16.3 \\
Needed additional dose of misoprostol & 7 & 1.5 \\
Fetus was never expelled & 9 & 2.0 \\
Total & 461 & 100.0 \\
\hline \hline
\end{tabular}




\section{Known Side Effects of Medical Abortion}

Vomiting was the least mentioned side effect of both Mediprist and Misoprostol medication as shown in Tables 7 and 8 . As expected, most clients experienced cramps/pain after taking Misoprostol.

\section{Table 7: Clients' Experiences of Side Effects of Mediprist}

\begin{tabular}{lrr}
\hline \hline & \multicolumn{2}{c}{ Responses } \\
\cline { 2 - 3 } Side Effects of Mediprist & Number & Percent \\
\hline Cramps/pain & 218 & 47.3 \\
Bleeding & 137 & 29.7 \\
Nausea & 98 & 21.3 \\
Chills & 89 & 19.3 \\
Flushes/sweats & 86 & 18.7 \\
Diarrhea & 86 & 18.7 \\
Headaches & 85 & 18.4 \\
Dizziness & 77 & 16.7 \\
Vomiting & 62 & 13.4 \\
& & \\
\hline \hline
\end{tabular}

Table 8: Clients' Experiences of Side Effects of Misoprostol

\begin{tabular}{lrr}
\hline & \multicolumn{2}{c}{ Client Responses } \\
\cline { 2 - 3 } Side Effects of Misoprostol & Number & Percent \\
\cline { 2 - 3 } Bleeding & 432 & 93.7 \\
Cramps/pain & 415 & 90.0 \\
Chills & 151 & 32.8 \\
Diarrhea & 148 & 32.1 \\
Headaches & 144 & 31.2 \\
Flushes/sweats & 128 & 27.8 \\
Dizziness & 115 & 24.9 \\
Nausea & 104 & 26.6 \\
Vomiting & 80 & 17.4
\end{tabular}


Clients had very varying experiences with side-effects; the most mentioned side-effect experienced by clients after taking just the Mediprist was cramps/pain for which they generally took pain medication. After taking the second medication Misoprostol, the clients reported that nausea was the most mentioned side effect experienced; this is most likely an effect of the combination of the two medications. The majority of the clients (77.8 percent) reported that they did not feel any effects or changes in their body function which can be linked to the medication or abortion at the time of the study.

\section{Service Providers' Training and Knowledge about Medical Abortion}

It is essential that service providers are knowledgeable about the services they provide as this allows them to provide the services more professionally which will result in high acceptance and high satisfaction. All the interviewed providers are health professionals with the following technical qualification distribution: 10 midwives, 2 nurses and 1 medical assistant. The average number of years' service providers had worked in their respective health facilities at the time of the study was 6 years with highest being 17 years and the least, 1 year.

All interviewed service providers had received training to provide medical abortion services from at least one of the following organizations; Ipas, Marie Stopes International Ghana, and Gynuity in collaboration with Ghana Health Service between 2005 and 2009. The average number of years providers had been introduced to medical abortion is 4 years with a maximum of 9 years and a minimum of less than a year. There have been in previous years a few small-scale medical abortion studies mainly based in single facilities which some of the providers were exposed to, these have all been one-off, short period studies.

To ascertain the confidence level of providers in the provision of the MA services they were asked to rank their knowledge and understanding 
on the administration of the MA medication. A significant proportion of providers; 92.4 percent ranked themselves as having excellent and very good knowledge on the administration of MA medication. As shown in Table 9 only 7.6 percent ranked themselves as having good knowledge about the drug administration procedure. None ranked themselves as having poor knowledge. This corresponds with the percentage of providers who knew the accurate dosage of Mediprist.

Table 9: Ranked Provider Knowledge on Medical Abortion Drug Administration

\begin{tabular}{lr}
\hline \hline & \multicolumn{2}{c}{ Client Responses } \\
\cline { 2 - 2 } Knowledge about drug & Percent \\
administration & \\
\hline Excellent & 46.2 \\
Very good & 46.2 \\
Good & 7.6 \\
Total & $\mathbf{1 0 0 . 0}$ \\
\hline \hline
\end{tabular}

Almost all (92.3 percent) service providers knew the accurate and recommended dosage of Mediprist per case (200mg). Providers were asked about the ineligibility criteria for medical abortion service. As shown in Table 10, the most mentioned was history of allergy to prostaglandin, followed by chronic renal failure and confirmed or suspected ectopic pregnancy. Other ineligibility criteria mentioned were concurrent long-term corticosteroid therapy, hemorrhagic disorders or concurrent anticoagulant therapy and the least mentioned criteria was inherited porphyries.

Table 10: Service Provider Knowledge of Ineligibility Criteria for Mediprist

Ineligibility criteria

History of allergy to prostaglandin

Confirmed or suspected ectopic pregnancy

Chronic renal failure

Concurrent long-term corticosteroid therapy

Hemorrhagic disorders or concurrent anticoagulant therapy

Inherited porphyries
Responses

Number Percent

7

53.8

$6 \quad 46.2$

$6 \quad 46.2$

$4 \quad 30.8$

$3 \quad 23.1$

$1 \quad 7.7$ 


\section{Satisfaction and Acceptance of Medical Abortion}

The acceptance of a new intervention in a general population depends significantly on the level of satisfaction experienced by initial users. Aggregated levels of satisfaction generally give a more accurate level of satisfaction among the general population.

The level of satisfaction derived from the medical abortion service was measured by both client and provider satisfaction. Providers of reproductive health care services including medical abortion services are a critical component in the successful introduction and implementation of any health intervention policy, program or product. Their satisfaction, comfort and acceptance of a product and/or a service allows for better provider-client interaction generally leading to higher client satisfaction rates. In the case of providers, about 11 out of the 13 providers indicated that they were satisfied with the product, the other two providers felt they were not entirely certain of the efficacy of the medication, however almost all (12 out of 13 ) the service providers were of the opinion that clients were satisfied with the product. This shows the level of acceptance of the product by service producers which will be pivotal in scaling up of the program to a larger population.

As can be seen from Table 11, about 94 percent of the clients were satisfied with the medication abortion procedure. However, about 4 percent were indifferent and about 3 percent were not satisfied with the medical abortion procedure.

Table 11: Percent Distribution of Clients by Level of Satisfaction

\begin{tabular}{lcc}
\hline & \multicolumn{2}{c}{ Responses } \\
\cline { 2 - 3 } Levels & Number & Percent \\
\hline Very Satisfactory & 201 & 43.6 \\
Satisfactory & 230 & 49.9 \\
Indifferent & 17 & 3.7 \\
Unsatisfactory & 5 & 1.1 \\
Very Unsatisfactory & 8 & 1.7 \\
Total & 461 & 100 \\
\hline
\end{tabular}


The level of client's satisfaction with the medical abortion procedure was translated in their confirmation that they would recommend the procedure to other friends, family and relations as well as choosing the procedure again in the future should it become necessary. About four in five (82.9 percent) clients indicated they will select the method again, while about 90.0 percent indicated that they will recommend the method to their family and friends.

\section{Difficulties and Challenges of Medical Abortion in Ghana}

The most mentioned challenge associated with the provision of medical abortion as reported by the providers is the persistent calls they received from clients. According to the providers, there is an associated level of uncertainty because they usually cannot tell exactly the severity of what really is happening to the client. Some providers also indicated that, for a few clients (about 7 clients), there was a need to repeat the Misoprostol which they were not very comfortable in administering. Finally, one provider indicated that failure to get call back from clients who took the medication home is usually disturbing because one cannot tell what might have happened to them.

Table 12: Provider Challenges Associated with Medical Abortion

\begin{tabular}{lcc}
\hline & \multicolumn{2}{c}{ Responses } \\
\cline { 2 - 3 } Challenges & Number & Percent \\
\hline No challenges & 7 & 53.8 \\
Persistent calls from client & 3 & 23.1 \\
Additional dose of Misoprostol & 2 & 15.4 \\
No call back because client took drug home & 1 & 7.7 \\
Total & 13 & 100 \\
\hline
\end{tabular}

Clients on the other hand had varying experiences during medical abortion process. Abdominal pains and/or waist pains were the most mentioned worst experiences associated with the procedure. This was followed by abdominal cramps and excessive bleeding/discharge. 


\begin{tabular}{lrr}
\hline \hline & \multicolumn{2}{c}{ Client's Responses } \\
\cline { 2 - 3 } Worst Experience & Number & Percent \\
\hline Abdominal pains or waist pains & 185 & 32.3 \\
Abdominal cramps & 99 & 17.3 \\
Excessive bleeding / Discharge & 79 & 13.8 \\
No side effect & 18 & 3.1 \\
Vomiting & 17 & 3.0 \\
Bleeding & 15 & 2.6 \\
Uncomfortable & 13 & 2.3 \\
Nausea & 12 & 2.1 \\
Very painful like during labor & 12 & 2.1 \\
Severe chills / offensive odor / feverishness & 11 & 1.9 \\
Pregnancy not completely terminated & 9 & 1.6 \\
Weakness in my legs and joints & 8 & 1.4 \\
Headaches & 8 & 1.4 \\
Diarrhea & 6 & 1.0 \\
Extra money spent for pads & 6 & 1.0 \\
Severe menstrual pains & 4 & 0.7 \\
Needed additional dose for a complete expulsion & 4 & 0.7 \\
Surgical method needed for completion & 4 & 0.7 \\
Loss of appetite & 2 & 0.3 \\
Discharge of blood clots & 1 & 0.2 \\
Had no significant side effect & 28 & 4.9 \\
\hline \hline
\end{tabular}

The best experience of the entire process according to the clients was the expulsion of product of conception within a short time. They also indicated that the procedure was very effective and for some of them, bleeding was just like normal menstrual flow. 
Table 14: Percent Distribution of best Experience of Procedure by Client:

\begin{tabular}{lrr}
\hline \hline & \multicolumn{2}{c}{$\begin{array}{c}\text { Client's } \\
\text { Responses }\end{array}$} \\
\cline { 2 - 3 } Best Experience & 148 & 29.2 \\
\hline Had an expulsion of the fetus within short time & 77 & 15.2 \\
Bleeding was just like normal menstrual flow & 59 & 11.6 \\
It was very effective & 43 & 8.5 \\
Medication was easily taken & 28 & 5.5 \\
Happy about the complete abortion & 21 & 4.1 \\
Affordable & 11 & 2.2 \\
Ensures more privacy & 9 & 1.8 \\
Nothing was good about this procedure & 6 & 1.2 \\
To avoid surgical method & 6 & 1.2 \\
Can do the insertion yourself & 6 & 1.2 \\
More effective than Misoprostol alone therapy & 5 & 1.0 \\
Avoided any physical trauma / pains & 5 & 1.0 \\
Checked and monitored by health providers & 4 & 0.8 \\
Pain was just for a short while & 3 & 0.6 \\
Coming to the facility to have it done & 2 & 0.4 \\
Severe abdominal cramps & 2 & 0.4 \\
The provider was always nice to me & 26 & 5.1 \\
No side effect / No complication & & \multicolumn{1}{c}{ Percent } \\
& & 5 \\
\end{tabular}

\section{Scaling up and Sustainability of Program and Product Services}

Scaling up and sustaining the program will depend on availability of the products and affordability of the service. Same as charges for MVA services, an average price of $\mathrm{GH} \$ 40$ was mentioned by service providers from both the private and public sector as the recommended amount clients should pay for the service. To ensure that more women have access to this life saving procedure, more than fifty percent of the interviewed service providers recommend that there should be intense counseling and education about the procedure. 


\section{Conclusion}

The principal focus of this documentation study is multifold. It concerns the perception, acceptance of the methods by clients who opt for it. It also documents from the client's perspective, acceptability, side effects associated with the method, and finally from providers, comfort in the provision of the service. The study further examined the skills and quality of service providers of medical abortion offered to their clients. The mean age of the clients was 25.8 years with $13.2 \%$ of them in their teen ages. The majority of them (55\%) had never married; the average number of children ever born (life birth) is one while the average number of pregnancy experienced is about three.

Providers took clients through counseling and allowed clients to choose a method, approximately 93 percent of the clients reported that providers gave them sufficient information on methods during their first counseling consultation. It is also important to note that, about 50 percent of the clients had medical abortion in mind before visiting the facility, whiles about 48 percent had MVA/EVA in mind. Among the clients who took the Misoprostol at home, about 78 percent of them reported that they preferred to be alone during the drug administration. This reinforces the notion that typically, women who go in for an abortion would not want it to be known to others. This also highlights the fact that due to the high stigmatization of the procedure, nobody wants to be publicly associated with abortion. Acceptability of medical abortion was very high, about 81 percent of the clients indicated that they will use the method again if they had to, while 89.5 percent indicated that they will recommend the method to their friends, approximately 85 percent of the providers were satisfied with the product.

The most noted side effect of Misoprostol was cramping. Among those who reported of side effect from the medical abortion process, 62.9 percent required some pain medication and treatment. Approximately 78 percent of the clients did not feel any effect or changes in their body 
as a result of medical abortion at the time of the study. Whiles more than 80 percent of the clients' experienced complete expulsion within 24 hours after administration of Misoprostol, about 16 percent had their expulsion after 24 hours with two percent needing additional dose and two percent needing a surgical completion.

Although the study showed high satisfaction with the method from clients and providers, the study identified one major challenge which needs to be addressed. This challenge has to do with getting clients to return to the facility for a follow-up visit where they would be examined to ascertain complete expulsion. Counseling should be intensified such that clients will feel the importance in them returning to the facility for a follow-up visit.

There are several advantages and disadvantages to either the surgical or medical abortion. The major advantage that the medical abortion has over the surgical is that the risk of surgery and use of anesthesia is avoided and the medical abortion procedure is generally less painful. The main disadvantages of medication over surgical abortion is that the duration for completion of the process is longer and is generally not recommended after a certain gestation period.

Overall the study has shown that medical abortion is a viable option for Ghanaian women, an overwhelming number of those who have benefitted from the procedure are content and will use or recommend it. The report shows that in Ghana, the women who used the procedure had no life threatening side effects at the time of their review visit. Most of the women interviewed reported headaches and cramps which are well known and documented side effects. Based on the findings of this report, it is highly recommended that more providers get trained in the provision of the service and most importantly the complementary counseling that it requires. The products and service should be made easily accessible and available to all women especially the vulnerable in order to stem the mortality rates associated with unsafe abortion. This study has shown that medical abortion is an effective method for 
first trimester up to 56 days of amenorrhea abortion; however medical abortion should not be viewed as a replacement but rather an alternative to surgical abortion. 


\section{Reference}

Adanu, R.M. and E. Tweneboah. 2004. "Reasons, fears and emotions behind induced abortions in Accra, Ghana." Research Review NS 20.2: $1-9$.

Ahiadeke, C. 2002. "The incidence of self-induced abortion in Ghana: what are the facts?” Research Review NS 18.1:33-42.

Creinin MD. 2000. Medical abortion regimens: Historical context and overview. American Journal of Obstetrics \&Gynaecology; 183:S3-S9.

Criminal Code of Ghana, 1960.(1985). Abortion or miscarriage. Act 29. Sections 58-59 and 67. Law No. 102.

Ghana Statistical Service (GSS), Ghana Health Service (GHS), and Macro International. 2009. Ghana Maternal Health Survey 2007. Calverton, Maryland, USA: GSS, GHS, and Macro International.

Ghana Statistical Service (GSS), Ghana Health Service (GHS), and ICF Macro. 2009. Ghana Demographic and Health Survey 2008. Accra, Ghana: GSS, GHS, and ICF Macro

Grimes, D.A., J. Benson, S. Singh, M. Romero, B. Ganatra, F.E. Okonofua and I.H. Shah. 2006. "Unsafe abortion: the preventable pandemic." The Lancet, Sexual and Reproductive Health Series.

Henry, R. and C. Fayorsey. 2002. Coping with pregnancy. Experiences of adolescents in Ga Mashi, Accra. Calverton, Maryland USA: ORC Macro.

Morhee, R.A.S. and E.S.K. Morhee. 2006. "Overview of the law and availability of abortion services in Ghana." Ghana Medical Journal 40: 80-86. 
Spitz I, Bardin C, Benton L, Robbins A. Early pregnancy termination with mifepristone and misoprostol in the United States. N Eng J Med. 1998; 338: 1241-1247

The Abortion Pill: Medical Abortion with Mifepristone and Misoprostol. $<$ http://www.fwhc.org/abortion/medical-ab.htm $>$, accessed Jan. 10, 2011.

Yeboah, R.W.N. and M.C. Kom. 2003. "Abortion: the case of Chenard ward, Korle Bu from 2000 to 2001." Research Review NS 19.1: 57-66. 


\section{Appendix}

Table 15: Study Sample by Socio-Demographic Characteristics

\begin{tabular}{lrr}
\hline \hline Socio-demographic characteristics & Percent & Number \\
\hline Age group & & \\
$15-19$ & 13.2 & 63 \\
$20-24$ & 32.3 & 154 \\
$25-29$ & 30.6 & 146 \\
$30-34$ & 14.5 & 69 \\
$35-39$ & 6.3 & 30 \\
$40-44$ & 3.1 & 15 \\
& & \\
Marital Status & & \\
Never married & & \\
Married & 55.0 & 262 \\
Cohabiting & 26.3 & 125 \\
Widowed & 15.8 & 75 \\
Divorced & 0.4 & 2 \\
Separated & 1.5 & 7 \\
& 1.1 & 5
\end{tabular}

Highest Level of Education

No schooling

$6.3 \quad 30$

Primary

$11.1 \quad 53$

Middle/JSS/JHS

27.1

129

$\mathrm{Sec} / \mathrm{SSS} / \mathrm{Tec} /$ Vocational

35.1

167

Higher

20.4

97

\section{Religion}

Christianity

89.5

Islam

8.6

Traditionalist

0.2

No religion

1.3

Other

0.4

2




\section{Ethnicity}

Akan

49.2

232

Ewe

16.7

79

Ga-Dangme

$19.1 \quad 90$

Mole Dagbani

$10.2 \quad 48$

Guan

2.8

Other

Trading/Vending for employer

$2.1 \quad 10$

Trading/Vending for oneself

5.5

26

Apprentice

$22.3 \quad 106$

Student

6.9

33

Unemployed

23.6

112

Other

11.2

53

$1.7 \quad 8$ 